\title{
Solar Spectrum Forcing Due to Soil Particle Concentration
}

\author{
Pantipa Wonglakorn and Surat Bualert
}

\begin{abstract}
The Solar spectrum forcing Due to Soil Particle Concentration to study about difference solar energy 3 unit on September 2012 at Petchburi province, Thailand. MS-700, Spectroradiometer was used to determined energy at the wave length 300-1050 $\mathrm{nm}$ and short-wave solar radiation. The soil particle was used in the experiment. The result showed that the particulate matter was decrease the shortwave radiation energy. The highest decreasing rate was near infrared range (-0.97\%), it showed slightly effect on ultraviolet range $(0.11 \%)$ and visible light rangeand $(0.87 \%)$. The soil particle showed significantly effect on the proportion of short wave radiation energy. At the visible light showed percentage is the highest in $450-490 \mathrm{~nm}$ $(16.0 \%)$ the lowest in $380-450 \mathrm{~nm}(11.0 \%)$.
\end{abstract}

Index Terms-Visible light, solar spectrum, soil particle, proportion of short wave radiation.

\section{INTRODUCTION}

Solar radiation is the main source of energy that radiate form Electronic wave which cause physical and biological processes on the Earth. The earth receives short-wave radiation from the sun [1]-[4]. At $12.00 \mathrm{am}$ is the period which was the lowest light absorption and light scattering due to the lowest distance between earth and sun. As a result, all of the radiation is effective [5]-[11].

The incoming short wave solar radiation is short-wave radiation which can reflect and scatter to the atmosphere. Soil particle in the atmosphere was considered as environmental problem due to increase with economic growth. The 24-hours ambient standard of total suspended particulate (TSP) is $330 \mu \mathrm{g} / \mathrm{m}^{3}$. Diameter of soil particle is vary and larger than $500 \mu \mathrm{m}$. It can be suspended in the atmosphere for 2-3 minutes before falling to the ground by gravity and wind. The dust suspended in the atmosphere for long. Particulate matter less than $10 \mu \mathrm{m}$ is usually due to a low speed fall to the ground [12], [13].Which are capable of scattering into the earth's atmosphere. It have colder than normal and absorption of radiation on the earth's surface hotter than normal [14] Therefore, the composition of the atmosphere changes. May affect the balance of the transfer of solar radiation in the atmosphere. This could result in long-term climate conditions.

\section{MATERIAL AND METHOD}

\section{A. Study Area}

Manuscript received December 5, 2012; revised February 3, 2013.

The authors are with the Environmental Science Department, Faculty of Science, Kasetsart University. 50 Namwongvan Rd, Chatuchak Bangkok, Thailand (e-mail: giftcy_pp@hotmail, com,surat.b@ku.ac.th).

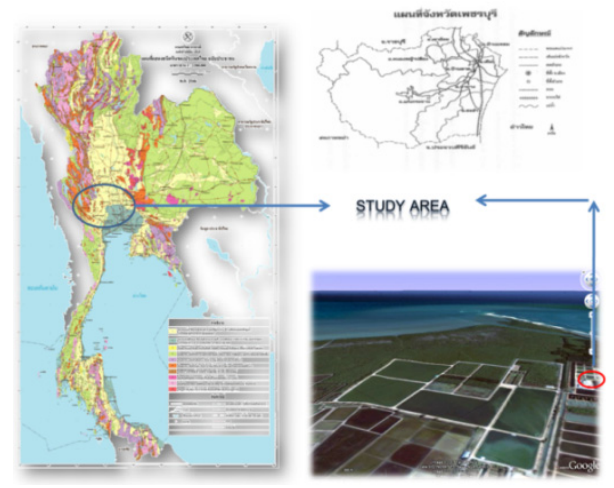

Fig. 1. Study area at Phetchaburi Province, Thailand.

The experiment was conducted at the experimental site of The King's Royally Initiated LeamPhakBia Environmental Research and Developmental Project (the Royal LERD-project) at Phetchaburi Province, Thailand.

\section{B. Field Experimental}

Field experiment was set up in September 2012. The measurement was used three Spectroradiometers, MS700 to measure and compared shortwave energy at the difference conditions. The measurement period was between $11 \mathrm{am}$ -14am.due to avoid the effect of the sun angle. The experiment contains three units which are:

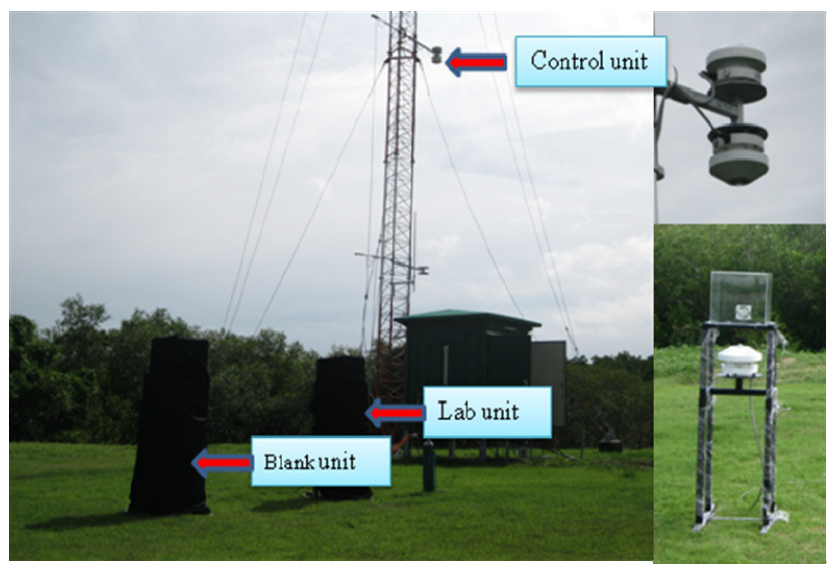

Fig. 2. Field Experimental

1) Control Unit is the unit for measuring the incoming solar radiation which is installed MS-700 at a height of 10 meters. The MS700 is the spectroradiometer for measuring energy of the sun radiation at the continuous wave length or light spectrum (300-1050 nm).

2) Blank Unit is the unit for measuring the effect of Trial Chamber. It made from Acrylic box at the packing cube shaped particle size $300 \times 300 \times 300 \mathrm{~mm}$. Under the chamber, MS-700 was installed to measure the energy of solar radiation which passed through the blank chamber.

3) Laboratory Unit is the unit for measuring the effect of soil particle inside the Trial Chamber. The chamber was 
filled with soil particle at difference concentrations. MS-700 was installed to measure the energy of solar radiation which pass through the chamber contained soil particle.
The experiments were conducted using three MS-700 Spectroradiometers, which were measured at the same time between 11:00 to 14:00 am (Fig. 1).

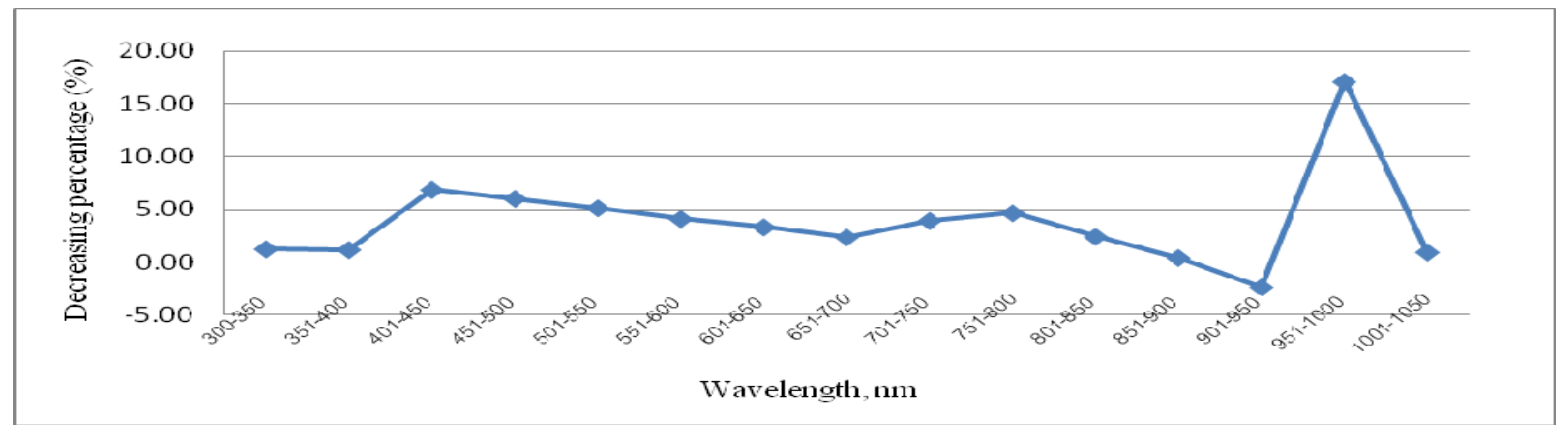

Fig. 3. Decreasing percentage (\%) of short wave radiation due to particulate matter at the range of 300-1050 nm

TABLE I: PROPORTION AND PERCENTAGE OF SOLAR ENERGy IN ULtRAVIOLET, Visible LiGHT AND NEAR INFRARED WAVE LENGTH

\begin{tabular}{cccc}
\multirow{2}{*}{ Experiment units } & \multicolumn{3}{c}{ Percentage of solar energy (\%) } \\
& $300-380 \mathrm{~nm}$ & $380-750 \mathrm{~nm}$ & $750-1050 \mathrm{~nm}$ \\
\hline Control unit & 16.73 & 54.50 & 28.77 \\
Blank unit & 1.13 & 59.72 & 39.16 \\
Lab unit & 1.02 & 58.85 & 40.13 \\
\hline
\end{tabular}

TABLE II: PROPORTION AND PERCENTAGE OF VisiBLE Light ENERGY

\begin{tabular}{cccccccc}
\hline \multirow{2}{*}{ Experiment units } & \multicolumn{5}{c}{ Percentage of visible light energy (\%) } \\
& $380-450 \mathrm{~nm}$ & $450-475 \mathrm{~nm}$ & $475-495 \mathrm{~nm}$ & $495-570 \mathrm{~nm}$ & $570-590 \mathrm{~nm}$ & $590-620 \mathrm{~nm}$ & $620-750 \mathrm{~nm}$ \\
\hline Control unit & 11.0 & 16.0 & 16.0 & 15.6 & 14.8 & 14.5 \\
Blank unit & 9.5 & 15.6 & 15.8 & 15.7 & 15.3 & 15.3 \\
Lab unit & 10.1 & 15.1 & 15.4 & 15.5 & 15.4 & 15.1 \\
\hline
\end{tabular}

Equation (1) is the effect of soil particle on the short-wave solar radiation defined as the difference of incoming solar energy and the energy that was loosed by the soil particle and the chamber. The incoming solar energy was measured by the control unit. The energy that was loosed by chamber and soil particle was measured by blank unit and lab unit respectively.

Effect of soil particle $=($ Control - Blank $)-($ Control-Lab $)(1)$

\section{RESULT}

The experiment was conducted on September 2012. The measurements showed difference solar energy in each experimental unit. The result showed that there were impacts on shortwave radiation in term of quantity and quality of shortwave radiation as follow:

\section{A. Decreasing of Shortwave Radiation Due to Particulate Matter}

Concentrations of soil particle were slightly effects on ultraviolet wave length (300-380 nm) by decreasing the solar energy in the wave length around $1.96 \%$.

At visible light $(380-750 \mathrm{~nm})$, the decreasing rate was showed the significantly decreasing rate at $380-450 \mathrm{~nm}$ but it was slightly decreasing rate at $450-700 \mathrm{~nm}$. At $900-950 \mathrm{~nm}$, the decreasing rate was negative because of the effect of the chamber. At near infrared (750-1050 nm), the highest decreasing rate was $17.1 \%$ at $950-1000 \mathrm{~nm}$ (Fig. 3).

\section{B. Proportion of Shortwave Radiation}

1) Proportion between ultraviolet, visible light and near infrared

The shortwave solar radiation $(300-1050 \mathrm{~nm})$ was divided into three ranges, ultraviolet $(300-380 \mathrm{~nm})$, visible light $(380-750 \mathrm{~nm})$ and near infrared $(750-1050 \mathrm{~nm})$. The ratio of them was $1.0: 3.5: 1.7$. The largest proportion was the visible light energy $(54.5 \%)$. The near infrared and ultraviolet were $28.77 \%$ and $16.73 \%$ respectively (see Table I).

The proportion of shortwave radiations measured by control unit, blank unit and laboratory units were used to compare the effect of particle on the proportions of shortwave radiation energy. The result showed the proportion of shortwave radiation was changed by decreasing the energy 300-380nm and increased the energy 380-750 nm (see Table I).

The different between the proportions (laboratory and blank unit) was the effects of particulate matter in the chamber on proportion of short wave radiation. The highest different was in the range $620-750 \mathrm{~nm}$. It can conclude that the particulate matter was reduced visible light energy the short wave radiation energy by difference proportion. As the increasing proportion at $380-750 \mathrm{~nm}$ (visible light) and decreasing proportion at 300-380 nm (ultraviolet).

The result shows a good agreement to the recommends in Kuwate and Colorado. It reported that solar irradiation at Kuwate using SKr-1850 measured at different (347.5, 450, $550,650,700$ and $800 \mathrm{~nm}$ ). Show Ultraviolet region was 
weak (315-380nm). But in near infra-red region (700-800 nm) was high irradiation intensity [15]. Frequent new particle (NPF) in Colorado. An Ultraviolet Multifilter Radiometer (UV-MFRSR) measured solar irradiance 7 narrowband (300, 305, 311, 317, 325, 332and $368 \mathrm{~nm}$ ). Result NPF events are strongly correlated with the UV irradiance [16].

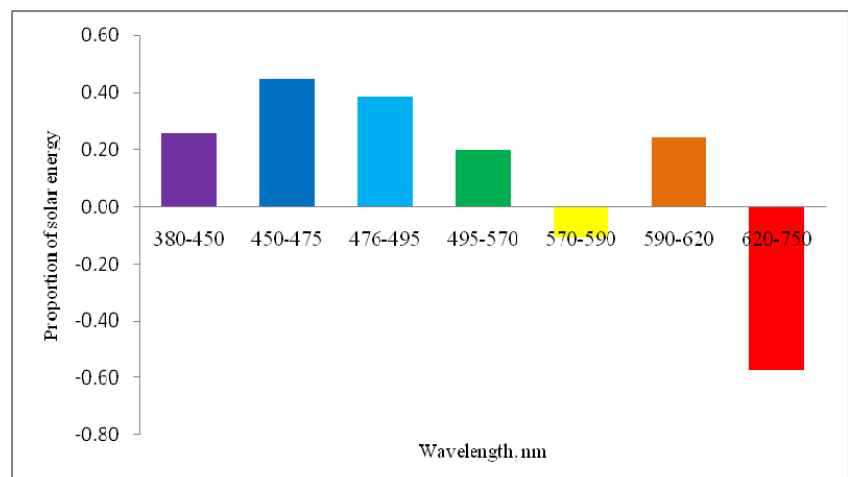

Fig. 4. Differential of the visible light proportion measured by control unit and laboratory unit

\section{2) Proportion of visible light}

The visible light energy was divided into 7 ranges, 380-450, 450-475, 475-495, 495-570, 570-590, 590-620, and $620-750 \mathrm{~nm}$. The result showed that the ratio of visible light energy measured by control unit was 11: 16: 16: 15: 14: 14: 12. Table II is showed that the largest proportion $(16.0 \%)$ was the range of 450-495 $\mathrm{nm}$ (indigo and blue) and the lowest was 380-450 nm (Purple). The highest proportion measured by blank unit and laboratory unit was $15.75 \%$ and $15.37 \%$ respectively at $475-495 \mathrm{~nm}$. The lowest proportion was measured by blank unit and laboratory unit were $9.47 \%$ and $10.06 \%$ respectively at $380-450 \mathrm{~nm}$. Compared the proportion measured by control unit to the proportion measured by blank unit and laboratory unit, the proportion was decreased at $380-495 \mathrm{~nm}$ but it was increased in the range of 495-750 $\mathrm{nm}$ (see Table II and Fig. 4).

\section{CONCLUSION}

Shortwave radiation was forced to reduce the energy due to particle by $1.96 \%$ especially on near infra red energy $(950-1000 \mathrm{~nm})$. The energy decreasing was affected on the proportion of energy in difference wavelength. Ultraviolet was decreased by $0.11 \%$. Visible light was decreased by $0.87 \%$ and near infra-red was increased by $-0.97 \%$. Comparing to the non-particulate matter in the chamber in the natural condition (or control unit), the percentage of ultraviolet, visible light and near infra-red were $16.73,54.5$ and $28.77 \%$ respectively. The percentage of visible light (350-450 nm (purple), 450-475 nm (indigo), 475-495 nm (blue), 495-570 nm (green), 570-590 (yellow), 590-620 nm (orange), 620-750 $\mathrm{nm}$ (red) in the natural condition were $11.0,16.0,16.0,15.6,14.8,14.5$ and $12.1 \%$ respectively.

\section{ACKNOWLEDGMENT}

The research is financed by the King's Royally Initiated LeamPhakBia Environmental Research and Developmental Project.

\section{REFERENCES}

[1] K. Chankaw, "Near surface meteorology," Department of Conservation, Faculty of Forestry, Kasetsart University, Bangkok. 1979.

[2] "The air quality in the atmosphere," Pollution Control Department to monitor dust in the atmosphere, Air Quality and Noise Management Bureau, Bangkok, 2003

[3] N. Parnit, "Textbooks air pollution treatment system," Department of Industrial Works, Ministry of Industry, Bangkok, 2011.

[4] N. Halzianastassiou, C. Matsoukas, Fotiadi, K. Pavlakis, , E. Drakakis, D. Hatzidimitriu, and I. M. Vardavas, "Global distribution of Earth's surface shortwave radiation budget," Atosm. Chem. Phy., vol. 5, pp. 2847-2867, 2005.

[5] A. A. Lacis and J. E. Hansen, "Parameterization for the absorption of solar radiation in the Earth's atmosphere," Journal of Atmospheric Science, vol. 31, pp. 118-130, 1974.

[6] N. Manago, S. M. Bannu, and H. Kuze, "Seasonal variation of tropospheric aerosol properties by direct and scattered solar radiation spectroscopy," Journal of Quantitative Spectroscopy \& Radiative Transfer, vol. 112, pp. 285-291, 2011.

[7] J. L. Monteith and M. H. Unsworth, "Principles of environmental physics," University of Nottingham of Agriculture, pp. 71 -74, Edward Arnold Ltd. London, 1990.

[8] R. Nessler, E. Weingartner, and U. Baltensperger. "Effect of humidity on aerosol light absorption and its implications for extinction and the single scattering albedo illustrated for a site in the lower free troposphere," Aerosol Scince, vol. 36, pp. 958-972, 2005.

[9] E. Pettit, "The sun and stellar radiation in astrophysics," J. Hynek Ed. New York. McGrawHill, pp. 703, 1951.

[10] H. Riehl, "Introduction to the atmosphere," Mc Graw - Hill Book Comp, Inc. New York. U.S.A. 1965.

[11] Assessment of Solar Energy Balance due to Land Cover Change in Petchaburi Province and Related Areas, The King's Royally Initiated LeamPhakBia Environmental Research and Developmental Project, 2011.

[12] A. A. Hady, Periodical Analysis of Solar Irradiation at Kuwate and Its Climate Effects, Published by Elsevier science Ltd, vol. 14, no.1-4, pp. 193-198, 1998.

[13] A. G. Hallar, D. H. Lowenthal, G. Chirokova, R. D. Borys, and C. "Wiedinmyer. Persistent daily new particle formation at a mountain-top location," Atmospheric Environment, vol. 45, pp. 4111-4115, 2011.

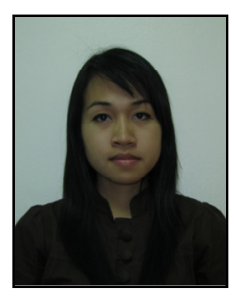

Pantipa Wonglakorn was born on 21 September 1987 in Sisaket. She is now working in Faculty of Environment, Kasetsart University, 50 Ngam wong wan Rd. Chatuchak, Bangkok, Thailand 10900. She got her Bachelor of Environment Science (B. Sc.)

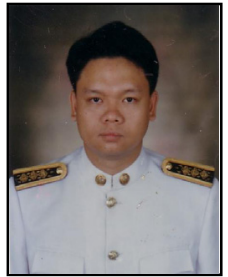

Surat Bualert was born on 8 August 1968 in Bangkok. He is now working as an assistant professor in dept of Environmental Science, Faculty of Environment, Kasetsart University, 50 Ngam wong wan Rd. Chatuchak, Bangkok, Thailand 10900. He has already got his $\mathrm{Ph} . \mathrm{D}$. Air Pollution. 